\title{
MULHERES E CRIANÇAS KAINGANG DA ALDEIA ICATU/SP: ETIQUETAS DE CONVIVIALIDADE
}

\author{
Thais Regina Mantovanelli da Silva
}

\begin{abstract}
RESUMO
0 presente artigo propõe discutir as relações entre mulheres Kaingang da aldeia Icatu, no estado de São Paulo, suas crianças e o espaço das casas. 0 que a etnografia mostra é a primazia de etiquetas de convívio pautadas pela lógica da não visitação entre pessoas de casas distintas. Tal esquema de convivialidade, que também se estende para as relações entre adultos e crianças, permite a não mistificação da imagem de criança indígena como mensageira ou livre de restrições a certos convívios. Mostra ainda que índios no estado de São Paulo formulam criativamente suas ações trazendo questões importantes para o debate da etnologia indígena, muito além das teorias de aculturação e assimilação, ao qual foram associados.
\end{abstract}

Palavras-chave: Convivialidade. Kaingang. Mulheres. Casa.

1 Doutoranda em Antropologia Social pelo PPGAS/UFSCar. 0 presente trabalho é fruto da dissertação de mestrado: Crianças invisíveis da Reserva indígena Icatu/SP, defendida no Programa de Pós-Graduação em Antropologia Social da UFSCAR. E-mail para contato: thaisremantovanelli@gmail.com 


\title{
WOMEN AND CHILDREN OF THE VILLAGE KAINGANG ICATU/SP: LABELS OF CONVIVIALITY
}

\begin{abstract}
This article aims to discuss the relationship between women who live in Kaingang Icatu village, in the state of São Paulo. Their children and the space of the houses are also investigated. This ethnography shows the primacy of labels convivial guided by the logic of non-visitation between people from different houses. Such a scheme of conviviality, which also extends to relationships between adults and children, enables not mystification image indigenous child as a messenger or free from restrictions to certain convivial. It also shows that Indians in the state of São Paulo creatively formulate their actions bringing important issues to the debate of ethnology, far beyond the theories of acculturation and assimilation, which were associated.
\end{abstract}

Keywords: Conviviality. Kaingang. Woman. House.

\section{INTRODUÇÃO}

G rande parte das etnografias sobre os mais variados povos ameríndios, que tem como foco descritivo-analítico concepções de criança e infância, apresentam as crianças como mensageiras preferenciais entre casas ${ }^{2}$. Segundo os autores, são elas que fazem as informações circularem entre espaços restritos, carregam informações sobre quantidade de caça de uma determinada família para outra, por exemplo.

Apesar da preocupação dos autores em não generalizar qualquer imagem ou conceito acerca da criança e do período de vida entre o nascimento e a idade adulta, a tipificação "mensageira" ganhou grande repercussão na etnologia indígena, especialmente em pesquisas cujo foco era crianças. Parecia que, finalmente, as crianças ganhavam estatuto de importância no debate antropológico: para além de suas brincadeiras, eram elas quem transportava informações entre grupos de adultos interditos. Mesmo sendo essa associação criança-mensageira de suma importância aos debates da Antropologia da Criança, o que minha etnografia, entre os Kaingang paulistas da aldeia Icatu, mostra é algo diverso.

\footnotetext{
${ }^{2}$ Para uma discussão mais apurada acerca da bibliografia da antropologia da criança, ver: Cohn (2005).
} 
De maneira inesperada, pude observar que as crianças da aldeia Icatu pouco circulavam entre as casas e mesmo pelos espaços da aldeia. A espacialidade das crianças veiculava-se principalmente à casa de suas mães, tias e avós maternas.

Enquanto elaborava projeto de pesquisa ${ }^{3}$, parti da conviç̧ão que para encontrar crianças bastava transitar pela aldeia. Na aldeia Icatu, no entanto, por mais que andasse não as via em lugar algum. Ao perguntar sobre as crianças para duas mulheres da aldeia, obtive como resposta: "ora, quando não estão na escola, estão nas suas casas". Crianças em suas casas, não era exatamente o que eu tinha em mente quando me propus a pesquisar crianças indígenas.

De todo modo, a me deparar com as inusitadas crianças da aldeia Icatu, tive que readequar minha tecnologia de pesquisa. Essa readequação ocorreu em favor da etiqueta de convívio cultivada localmente: não circulação entre casas, acesso restritivo a pessoas de gêneros opostos e de categorias etárias distintas. Ao ter de cumprir tais modos de relacionamento, fui alocada para varandas de duas casas, cujas donas tornaram-se minhas principais interlocutoras de pesquisa.

A proposta deste artigo é apresentar etnograficamente as maneiras preferenciais de convívio na aldeia Icatu, formada pelo encontro de duas etnias: Terena e Kaingang. 0 ponto de vista privilegiado aqui é o das casas Kaingang, ou seja, casas cujas mulheres situam-se como parte desse grupo étnico e que se tornaram minhas anfitriãs.

Para cumprir sua proposta, o artigo está dividido em quatro partes: na primeira, apresento alguns dados históricos sobre a aldeia Icatu e considerações sobre sua origem e chegada dos Terena; em seguida, descrevo as relações entre mulheres e crianças, destacando a concepção das mulheres sobre as crianças de suas casas; posteriormente, mostro como as casas e o domínio das mulheres relacionam-se com a política da convivialidade local; e finalmente, à guisa de conclusão, destaco a não circulação entre pessoas de casas distintas como uma política de controle tanto de pessoas quanto de informação.

\footnotetext{
${ }^{3} 0$ presente artigo é parte de um capítulo de minha dissertação de mestrado, ver: Mantovanelli (2012). Atualmente desenvolvo pesquisa de doutorado, pelo mesmo programa, sobre a relação entre os Xikrin da Terra Indígena Trincheira-Bacajá e a usina hidrelétrica de Belo Monte.
} 


\section{AldeIA ICATU: História do ENCONTRO ENTRE KAINGANG E TERENA}

Os Kaingang são tema recorrente na etnologia indígena, abordados desde pesquisas que tematizam graus de aculturação e civilização ${ }^{4}$ até trabalhos mais recentes sobre formação de pessoa, faccionalismo e política, xamanismo, variação linguística, cosmologia 5 . Desde seu aparecimento, os Kaingang nunca deixaram de ser interesse das pesquisas antropológicas e linguísticas.

Segundo registros colhidos por D'Angelis (2003), os Kaingang apareceram na literatura antropológica e em registros de viajantes, no final do século XVIII, com diversas nominações distintas: como Botocudo, Caingang e Coroados. As variações linguísticas entre cada grupo chegam a somar pelo menos quatro dialetos distintos.

Narrados por Lévi-Strauss (1970), no famoso livro Tristes Trópicos, como um dos povos já contaminados por processos de aculturação, devido ao intensivo contato com as sociedade nacional, e desconsiderados pelo Projeto Havard Brazil Central (PHBC) sob a mesma justificativa, os Kaingang passaram a receber menos enfoque pelas pesquisas antropológicas.

As pesquisas de Coelho dos Santos (1973) e Urban (1978) trouxeram os Kaingang de volta à pauta da antropologia indígena, questionando as afirmações do contágio da assimilação, apresentadas por Maybury-Lewis (1979) feitas durante os anos 1960 .

A chegada dos Kaingang à região do Estado de São Paulo é apresentada por pesquisadores e pelos Kaingang através de várias versões. A versão que se conta na aldeia Icatu relaciona-se a uma disputa ocorrida entre grupos de Kaingang no Paraná, devido à pressão de intensificação de contato com o homem branco. Com essa divisão, parte do grupo passou a caminhar no sentido norte chegando à região do estado de São Paulo, onde ficaram conhecidos como os "índios arredios do rio Peixe".

\footnotetext{
${ }^{4}$ Para uma avaliação dos trabalhos publicados sobre a língua e cultura dos Kaingang no século XX, entre 1851 até 1951, ver: D’Angelis (2003). Dados históricos sobre formação dos territórios Kaingang nos estados de São Paulo, Paraná e Rio Grande do Sul disponíveis também no site do Portal Kaingang: http://www.portalkaingang.org/Primeiros100anos.pdf.

${ }^{5}$ Principais autores: Schaden (1953,1959), Tommasino (1995), Fernandes (1998), Mota (1998), Haverroth (1997), Gonçalves da Rosa (2004), Veiga (1994, 2000), D’Angelis (1992, 1998), Kurtz de Almeida (1998).
} 
Monteiro (1984, p. 45) afirma que até boa parte do século XX, o oeste paulista não tinha sido ocupado efetivamente por frentes de urbanização, e tratava-se de uma região desconhecida, cujos habitantes eram considerados perigosos e hostis. A partir desse período, várias frentes de colonização com caráter exploratório foram organizadas com comissões científicas, expedições religiosas, expansão cafeeira e construção de ferrovias. A colonização do oeste paulista desprendeu forças para apresentar e convencer os índios das maravilhas do mundo civilizado, mapear as áreas desconhecidas e afastá-los das áreas cobiçadas.

Dados fornecidos por Darcy Ribeiro e Barbosa em 1954, discutidos por Borelli (1984), afirmam que, antes do contato, a média populacional Kaingang no Estado de São Paulo girava em torno de 1.200 pessoas; após a pacificação, no ano de 1912, restaram 700 indivíduos e no ano de 1916 somavam apenas 200. Uma perda de mais de $80 \%$ da população dos Kaingang paulista (BORELLI, 1984, p.81).

Além dos fatores conhecidos como morte por conflitos e contaminação letal de doenças contagiosas, outro fator contribuiu para a baixa demográfica dos Kaingang da região de São Paulo: entre os quatro anos referidos não houve nenhum nascimento de crianças. 0 processo de enfrentamento dos Kaingang com membros da sociedade nacional, vinculados ao projeto de expansão ferroviária do interior paulista, quase exterminou os Kaingang da região. Incertos de seu futuro, os Kaingang optaram por não gerar mais crianças, de forma a estagnar 0 crescimento demográfico. Situação semelhante também foi descrita por Menget (2001) entre os Txicão ou Ikpeng que, pela incidência de doenças e fome que os levaram à transferência ao Parque Nacional do Xingu, onde tinham de conviver com povos xinguanos, considerados inimigos, optaram por não dar continuidade demográfica a seu grupo. Nos dois casos, dos Kaingang paulistas e dos Txicão ou Ikpeng do Parque Indígena do Xingu (PIX), o nascimento de crianças e a 0 crescimento populacional só foram reiniciados quando os grupos sentiram segurança em poder dar continuidade a si mesmos.

A presença dos Kaingang na região do oeste paulista é marcada por uma história de contato conflituosa com os agentes de ocupação agropecuária. Contrários ao que desejava a política progressista da época de ocupação do interior do Estado de São Paulo, os índios não aceitaram facilmente o aldeamento, a presença de colonos e o desenvolvimento agrícola de café na área. A existência da Reserva do Icatu é um exemplo dessa relação de conflito de interesses e atuação do Estado. 
Segundo Manizer (2006), o surgimento da Reserva Icatu resulta de uma atuação do Serviço de Proteção ao Índio (SPI) ${ }^{6}$ na "pacificação" dos bravos Kaingang do oeste paulista. A fim de diminuírem as tensões entre os índios e os agentes de ocupação, o SPI trouxe os Terena à região. Isso porque os Terena eram considerados pacificadores e conhecedores dos métodos de trabalho de produção agrícola e criação bovina. No início dos anos 1930, alguns grupos Terena da aldeia de Cachoeirinha, MS, foram transferidos pelo SPI para os Postos Indígenas do interior do Estado de São Paulo, com o objetivo de acalmarem os Kaingang e lhes ensinar técnicas de produção e cultivo agrícola. 0 Posto do Icatu foi um lócus preferencial para essa transferência dos Terena pelo SPI, os quais deveriam ensinar as regras de civilidade aos bravos Kaingang da região para que estes não mais atrapalhassem o processo de construção das linhas ferroviárias noroeste. Os Terena foram considerados pelos agentes de colonização como índios colonizadores, pacificadores, e com boas disposições para os mais diversos tipos de trabalho como: derrubada de matas, abertura de estradas e construção de fazendas.

A relação dos índios nessa região com os agentes colonizadores é acompanhada por uma trajetória de exploração, pela via da escravidão. Os anos entre 1640 a 1650 são apontados como o ápice do maior índice de índios administrados como mão de obra escrava no interior do Estado de São Paulo. Cidades como Itu, Jundiaí e Sorocaba são alguns exemplos desse tipo de utilização dos chamados povos Tapuia (MONTEIR0, 1984, p. 37).

A chegada dos grupos Terena como ação política do SPI é narrada em livro escrito por Keló-Maurício Pedro Campos (1999) ${ }^{7}$, produzido pelo MARI/USP e coordenado por Maria Aracy Lopes da Silva. Os Kaingang da aldeia Icatu fizeram questão de me mostrar o livro. A importância do livro, formatado em tipo brochura de grampos, está na forma como o surgimento do Icatu é narrado. As falas e descrições são dos Kaingang da aldeia. São eles contando a história de sua aldeia. Apesar de longo, considero valer a pena apresentar um trecho inteiro da narrativa.

\footnotetext{
${ }^{6}$ Órgão público, criado em 1910, que atuou nos processos de contato com implantação de políticas assimilacionistas dos povos indígenas ao estado nacional. Em 1967, decorrente de uma reestruturação do órgão, foi substituído pela Fundação Nacional do Índio (FUNAI), com uma política de salvaguarda dos povos indígenas em seus aspectos culturais. Sobre a criação do SPI e sua substituição pela FUNBAI, ver: Carneiro da Cunha (1987).

7 Keló-Maurício Pedro Campos. Kaingang: Pyry Nhenpe'ti. Kaingang: um sonhador. MARI/USP/FAPESP, Penápolis, 1999.
} 
Meu nome é Keló, um nome Terena, já no mundo dos brancos meu nome é Maurício Pedro Campos, sou casado com Lícia Vitor Pedro e temos três filhos. Vivemos na Comunidade Indígena Icatu, uma área de 295 hectares que fica entre os municípios de Braúna e Luiziania e também é conhecida como Reserva do Icatu. Meu pai, Hôienó (que vocês conhecem por Florentino Pedro), é índio Terena. Minha mãe, Ningua're Kuié (mas podem chamá-la de Catarina Campos Pedro), uma índia Kaingang, e por isso você já deve ter notado que convivem na nossa comunidade duas etnias diferentes. Vivemos juntos, em harmonia como se fossemos irmãos. [...] 0 nome Icatu, que foi dado pelo Serviço de Proteção ao índio (SPI), quando foi criada a reserva, é da língua Guarani, Icatu Poré, significa Lugar Bonito. [...] Porque será que o SPI escolheu dar um nome Guarani para uma reserva dos Kaingang? Há muito tempo atrás será que eles eram nossos vizinhos? Um grupo deles veio para o interior de São Paulo? Ainda não sabemos ao certo. 0 meu irmão Undeté, que vocês conhecem por Mario Pedro, contou-me que uma vez, quiseram mudar o nome da reserva para Capitão Kenkra, um valente Kaingang que andava fardado na aldeia, mas todos continuavam chamando o lugar de Icatu, o nome novo não pegou... [...] Quando o SPI foi fundado, em 1910, os seus funcionários trataram de "pacificar" os "terríveis" Kaingang, que "atrapalhavam" a construção da Estrada de Ferro Noroeste do Brasil que serviria para transportar 0 café ao porto de Santos. Atrapalhavam também os cafeicultores que tinham interesse em ampliar ainda mais suas fazendas para produzir mais café. Outra história que meu pai conta é que em 1914 foi inaugurado o Icatu, em terras que foram doadas por uma fazendeira. Então, provavelmente, não foi 0 Governo quem cedeu as terras, como em outras reservas indígenas, mas não temos certeza disso. [...] Por esse mesmo tempo, 1930, o SPI desenvolvia muitos tipos de trabalhos na reserva, criavam porco faziam plantações de café, de frutas (pomar), hortas... de modo que nossos pais contam que havia muita fartura na nossa reserva. O SPI muitas vezes chamava os Terena para virem trabalhar no Icatu e, quando terminava a empreitada, eles retornavam para o Mato Grosso do Sul. Foi aí que começou a amizade dos Kaingang com os Terena. Dez anos depois, por volta de 1940 começaram a chegar os primeiros Terena para ficar no Icatu, isso porque, os rapazes Terena começaram a trocar olhares com as moças Kaingang e vice-versa. Assim foi surgindo o amor entre eles, casaram-se e hoje o Icatu tornou-se uma comunidade que vive com muita harmonia e amor. 
Atualmente, o Estado de São Paulo conta com povos indígenas localizados em reservas espalhadas por seus territórios. Em comum na diversidade étnica nesse território está a proximidade e vizinhança com cidades interioranas ou com a capital do Estado. Essa proximidade, ou as relações de vizinhança que dela se supõem, resulta de um histórico antigo e sistemático de contato com frentes de colonização e sugerem especificidades nas formas como cada um desses grupos vivenciou e vivencia essas relações.

No caso de Icatu, que tem na sua origem a mistura de grupos étnicos diferentes, um dos efeitos da ação das frentes de contato foi fazer surgir um amor entre pessoas Kaingang e Terena. Meus interlocutores, sempre que possível, faziam questão de frisar a harmonia da convivência desses dois grupos na aldeia. Harmonia exaltada por Hôienó Florentino Pedro ao dizer que quando nasce uma criança de pais Kaingang e Terena, essa criança passa a ser das duas etnias. Quando cresce, a pessoa decide se quer ser mais Kaingang ou mais Terena. Essa escolha não precisa ser fixa, pode mudar ao longo da vida. Florentino exemplificou-me a questão citando seu filho: "Esse meu filho Maurício mesmo, era Terena quando criança e depois quis seguir mais a linha dos Kaingang e hoje ele é mais Kaingang que Terena".

A harmonia de viver em Icatu é relacionada pela boa convivência dos grupos Terena e Kaingang a mesmo tempo em que a escolha de se vincular mais a um grupo que a outro é feita ao longo da vida e pode ser desfeita, inclusive. Essa possibilidade mutati mutantis é vista de forma impressa em camisetas dos times de futebol nas aldeias: "Posso ser quem você é sem deixar de ser quem eu sou".

Apesar das relações destacadas de harmonia, o que se passa na aldeia Icatu é que tal ideal nunca se concretiza totalmente e as disputas entre casas mais Kaingang e mais Terena ocorrem cotidianamente, tanto de forma expressa quanto de forma velada. A própria disposição espacial das casas revela a associação mais Kaingang ou mais Terena de cada família que a habita. Existe, por exemplo, um espaço separado na aldeia onde estão situadas as chamadas casas da terenada. Essas são casas de Terena que não se misturaram matrimonialmente com membros das famílias de casas Kaingang, ou com membros de famílias misturadas que vivem há mais tempo na aldeia ${ }^{8}$.

\footnotetext{
${ }^{8}$ Ouvia com frequência de vários interlocutores "mais Kaingang" quando perguntava da área mais distante habitada da aldeia, apontando para as casinhas construídas lado a lado na parte mais alta do terreno, que aquela era a região da terenada. Nessas casas moram os Terena que mais recentemente chegaram ao Icatu. Seria interessante saber o ponto de vista dos Terena, habitantes
} 
Veladas ou não, as rivalidades entre as casas mais Kaingang ou mais Terena eram o tempo todo alvo de um esforço coletivo de pacificação e harmonia. Esse esforço constituía-se, principalmente, pelo comedimento da circulação de pessoas entre as casas, o que eu chamo, a título de alegoria, de lógica da não visitação. Se tal esforço mantinha as pessoas mais estáticas e mais fixadas às suas próprias casas de um lado, de outro, proporcionava uma relação de proximidade e um convívio intensos entre mulheres e crianças da mesma casa, mais especificamente entre avós, mães, filhas e netos das filhas.

\section{MULHERES E CRIANÇAS DA ALDEIA ICATU}

Minha expectativa de pesquisa quando iniciei meu trabalho de campo na aldeia Icatu era estar com crianças. Informada pela leitura de etnografias sobre crianças indígenas que descreviam seu intenso trânsito pelos espaços das aldeias, sua permanência nos lugares restritos a certos tipos de pessoas, e sua marcante dinâmica corporal e mobilidade pelos caminhos ${ }^{9}$, eu esperava caminhar com as crianças pela aldeia, acompanhar suas brincadeiras e suas ações cotidianas. Mas logo percebi que isso não seria possível na aldeia Icatu. Comedidas, as crianças ocupavam preferencialmente os espaços de suas casas e quintais, negando-se a conviver comigo em seus espaços de convívio.

Se invisíveis ou reclusas em seus quintais de um lado, de outro, as crianças eram assuntos favoritos das rodas vespertinas nas varandas das mulheres. Com um tom de uma quase disputa, as mulheres exibiam na fala seus filhos e netos, destacando-os como protagonistas do que há de melhor em termos de existência humana. Assim, as crianças da aldeia Icatu SP que estavam longe dos meus olhos, estavam em meus ouvidos, trazidas pelas falas de suas parentas ${ }^{10}$.

0 fato de eu não ter conseguido acesso às concepções das crianças sobre si e sobre os adultos não significa que elas não as tenham, ou que elas não construam seus sentidos e suas definições. Os motivos pelos quais não pude atingir as crianças em suas considerações diz algo importante acerca das relações vividas entre elas e os adultos.

dessas casas; mas, devido à minha relação mais direta com os Kaingang, não me atrevi a perguntar ou a visitar as casas Terena.

${ }^{9} 0$ livro organizado por Aracy Lopes da Silva e Angela Nunes (2002) é referência imprescindível dessa discussão acerca da mobilidade como característica das crianças indígenas.

${ }^{10}$ A descrição acerca das falas das mulheres em relação às suas crianças é tratada em: Mantovanelli (2014). 
0 distanciamento entre mim e as crianças foi compensado pela aproximação com as mulheres de duas casas da aldeia. E nas casas dessas duas avós-anfitriãs, eu passava os dias, as tarde e as noites. 0 convívio intensificado com as duas mulheres e suas filhas permitiu-me repensar metodologicamente a categoria criança e as formas de descrição possíveis. Mesmo não estando com as crianças em suas atividades, as crianças estavam o tempo todo próximas de mim através das falas de suas avós, mães e tias.

Essa relação mulher-avó-mãe-tia-criança não deve ser tomada de forma óbvia, como consequência de uma associação biológica que naturaliza esse tipo de relacionamento. Ou seja, quando digo que são as falas das parentas que me mostraram como as mulheres Kaingang do Icatu conhecem as crianças, não pretendo reforçar a noção biológica da relação consanguínea privilegiada entre mulheres e crianças. Não tomo como natural o fato de serem as mulheres que me informavam sobre crianças. Não pretendo solidificar a relação causal entre mulheres, genitoras, portanto mães e conhecedoras de crianças. As crianças eram assuntos favoritos das mulheres, mas não uma exclusividade das conversas femininas. Afinal, crianças também são assuntos dos homens. Além disso, as crianças também falam de si. No entanto, pela forma como fui situada no e pelo trabalho de campo, o ponto de vista dos homens e das próprias crianças sobre si não puderam ser aqui destacados. Respeitar as condições de pesquisa significa considerar válidas as considerações e ações de convivialidade ${ }^{11}$ em voga.

Descrever crianças a partir das mulheres, suas parentas, levou-me a refletir sobre circulação de pessoas, importância das casas, convivialidade, restrição e respeito, comedimento.

A partir de duas casas pude entender que se criança é assunto das conversas femininas, não se deve falar de qualquer criança. Fala-se sobremaneira das crianças pertencentes àquela ou esta casa: dos netos, sobrinhos e filhos das mulheres que compõem o segmento residencial. Assim, a avó de uma determinada casa fala dos seus netos, que são filhos e filhas de suas filhas, porque os filhos e filhas de seus filhos são assunto da avó da outra casa. Além do que, para se falar de criança é preciso que se tenha uma. Meninas solteiras e sem filho não costumam participar das varandas com as mulheres mais velhas.

11 Desde publicação de Overing (1991, 1999), o conceito de convivialidade, bem como os procedimentos éticos e estéticos relacionados aos modos de bem viver, tem sido discutido e rendido boas reflexões em etnografias sobre diversos grupos ameríndios. 
Além disso, ao se tomar criança como assunto, cada mulher ou um conjunto de mulheres parentas costuma eleger a criança que está mais próxima de si como exemplar máximo da perfeição humana. Juntas, elas destacam todas as qualidades da criança, considerando, por exemplo, o acesso de raiva $\mathrm{e}$ agressividade como uma característica superpositiva da personalidade. Caso estejam juntas, as mulheres de uma mesma casa tornam as crianças relacionadas a elas alvo de elogios, de história de contentamento. Em situações de encontro de mulheres de casas distintas, decorrente de alguma ocasião especial, as mulheres de cada segmento elencam as qualidades de suas crianças próximas como sendo as de maior expressão. Tal situação não desemboca em algum tipo de disputa sobre qual das crianças mencionadas é melhor que a outra. Para cada uma das mulheres, as crianças de suas falas são melhores do que as da fala da outra mulher. Por exemplo, dizer que uma criança é a melhor desenhista da aldeia permite que outra criança também possa assim ser referida pelos seus parentes, uma alegação de qualidades onde todas as crianças se tornam vencedoras, desde que lembradas pelas suas parentas.

\section{AS MULHERES E SUAS CASAS}

A discussão sobre casas na etnologia indígena ganhou especial destaque com as publicações de Vanessa Lea $(1986,1993,1994,2000,2012)$ acerca das casas Mẽbengôkre-Kayapó, a parir de sua definição de matricasas. Inspirada no debate de Levi-Strauss (1979) sobre Casas como uma instituição moral, a autora problematiza as matricasas mẽbêngôkre e suas linhas de transmissão de prerrogativas rituais, partes consumíveis de caça e bens materiais (nekretx).

A partir da definição das matricasas mẽbêngôkre, Lea $(1986,2012)$ propõe uma análise crítica ao modelo teórico dualista da relação antogonística entre centro da aldeia como espaço masculino e político versus periferia como espaço doméstico das casas, de caráter feminino e apolítico. Para a autora, relacionar as mulheres Jê, ou especificamente as Mebengokré, ao plano do doméstico, do biológico, como se cuidar de crianças fosse uma ação apolítica, constitui-se numa atitude deveras masculinizante e/ou descuidada dos etnólogos, defensores do modelo dualista, especialmente àqueles vinculados ao Programa Havard Brazil Central (PHBC).

O PHBC não somente relegou as mulheres à 'periferia' como também representou um passo adiante na caracterização da filosofia dualista 
que passou a sintetizar a perspectiva Jê-Bororo, acrescentando ainda a oposição biológico $\mathrm{x}$ social. Os homens são tidos como monopolizadores da vida cerimonial e política, enquanto as mulheres, menos plenamente sociais, mais próximas à natureza, em função de sua posição na 'periferia' da aldeia, próximas à floresta circundante, contentam-se com os afazeres domésticos - preparação dos alimentos e cuidado das crianças. Na visão, por exemplo, de Da Matta, a esfera de ação feminina privilegia os laços biológicos (portanto 'naturais') que unem a família nuclear (um casal e seus filhos), enquanto os homens são responsáveis por questões de ordem pública, ritual e jural (referente a direitos e deveres), articulando a sociedade como um todo (a comunidade aldeã). A vida feminina é representada como mais atomizada; as mulheres são tidas como incapazes de sublimar os interesses que dizem respeito a sua própria unidade doméstica, extensa e uxorilocal (o marido mora na casa da esposa). Para Turner, a sociedade Jê-Bororo é constituída de uma 'infraestrutura' doméstica e uma 'superestrutura' comunal masculina, permitindo aos homens dominar e controlar as mulheres que ocupam o nível inferior da estrutura social. Bamberger descreve o domínio feminino como 'fracamente social', com as mulheres desempenhando um papel quase inexistente em questões comunitárias. Ela conclui que: ‘A localização das mulheres na periferia da aldeia simboliza seu papel social apolítico e marginal na sociedade Kayapó' (LEA, 2000, p. 178).

Concordando com a crítica de Lea, meus dados etnográficos não mostraram haver uma relação antagonística entre espaço doméstico e público/cerimoninal. Nas palavras de Lea (1994, p. 266), duas irmãs ou primas paralelas podem ou não residir debaixo de um mesmo teto, mas de qualquer maneira, pelo fato de pertencerem a uma mesma linha uterina, são consideradas membros de uma única matricasa, caracterizada por seu patrimônio de bens herdáveis e referências mitológicas. Para Lea, a criança que nasce pertence à Casa da mãe e com isso afirma para os Mebengokré uma ideologia uterina que transmite as prerrogativas herdáveis. Assim, pertencer a uma casa não é ser seu morador, mas possuir vínculos de parentesco com a mulher, dona da casa.

As casas do Icatu, comandadas por mulheres, operam na vida política do cotidiano da aldeia e estão longe de poderem ser associadas a uma esfera doméstica num sentido apolítico do termo. Além disso, conformam o espaço de atuação do feminino, o espaço da primazia das mulheres, mães e avós. Não seria exagero dizer que as casas mais cheias de parentas são as mais importantes 
politicamente no Icatu e são aquelas em que a dona já possui netos e assim as filhas passam ali suas tardes. Essas casas das mulheres velhas, cujas famílias estão vinculadas à fundação da aldeia, gozam de prestígio entre os homens e são indicadas como as melhores companhias para pesquisadores. Assim, tão mais prestígio tenha uma casa e sua dona, mais influência política exerce nos acontecimentos da aldeia.

Um exemplo etnográfico elucidativo foi uma questão em relação à escola da aldeia, que dividiu a opinião das mulheres sobre se deveriam ou não continuar a matricular seus netos na escola local ou se deveriam transferi-los à escola da cidade de Braúna. 0 início do problema deu-se após a contratação de uma professora para a escola indígena. A professora contratada era da etnia Terena, recém-chegada à aldeia Icatu e que havia se casado com outro Terena da aldeia. A indignação de parte das mulheres, especialmente das casas Kaingang, referiu-se à contratação da recém-chegada à aldeia em detrimento de outra professora, de casa Kaingang, nascida no Icatu. 0 argumento do diretor de que a nova moradora era formada em pedagogia não serviu para acalmar os ânimos das mulheres das casas discordantes. Assim, as casas relacionadas retiraram suas crianças da escola da aldeia e as matricularam na escola da cidade, apesar de todas as tentativas de persuadi-las a mudar de ideia, não houve acordo: "Falamos para elas, é ruim para as crianças pequenas ir estudar na cidade porque é longe e tem que acordar muito cedo para pegar o ônibus. Não adiantou".

As casas do Icatu, através de suas donas, carregam um valor político-moral, um lugar das pessoas e de suas relações. As mulheres passam a ter sua casa após o casamento e, mesmo após o nascimento de seus filhos, continuam a pertencer à casa de sua mãe, cujas visitas são mantidas constantes. As donas das casas, que necessariamente são avós, não precisam visitar nenhuma outra casa; ao contrário, é a sua casa que se torna alvo de visitações. Ser a dona da casa visitada é ter prestígio tanto entre os membros da família, quanto entre os homens da aldeia. $\mathrm{E}$ para que se tenha uma casa visitada é preciso ter filhos, e preferencialmente filhas, e é preciso que estes filhos tenham filhos; é preciso ter netos, em suma.

Importante mencionar que as casas são também visitadas pelos filhos e seus filhos. No entanto, os homens que visitam a casa de sua mãe não permanecem na varanda com as mulheres. Ou, quando ficam, ocupam um lugar fora da rodinha feminina de artesanato. As visitas dos filhos costumam também ser mais ligeiras. Dificilmente vi homens passarem a tarde inteira na casa de sua mãe, como fazem suas irmãs. A relação preferencial no cotidiano das casas é entre avós, mães, filhas e netos. 
As opiniões de pessoas de determinadas casas são mensuradas em relação ao tempo de existência da casa na aldeia, tendo maior destaque casas que fundaram a Terra Indígena, casas que iniciaram o intercurso matrimonial entre as pessoas Kaingang e Terena.

As mulheres referem-se como donas de suas casas, tornando fundamental destacar a discussão realizada por Carlos Fausto (2008) entre a diferença crucial que o termo dono/maestria possui em relação à ideia de propriedade que nós designamos como fundamental para as relações com 0 que possuímos. Para 0 autor, em termos bastante gerais, o conceito de dono, no contexto amazônico dos Parakanã, envolve relações bastante diversas das que concebemos para definir aquele que possui algo e aquilo que se possui. Não há uma relação sujeito-objeto, de uma apropriação submissa entre os termos, nem uma primazia do sujeito que possui em relação àquilo que possui, abrangendo de coisas a pessoas, prerrogativas, artefatos, poderes, parentes, lugares. Deixando de lado as discussões realizadas pelo autor sobre as atribuições xamânicas e as apropriações da filiação e aliança entre os povos amazônicos, tomo aqui a indicação de que a posse possa ser pensada para além de uma relação entre dominante/sujeito e dominado/objeto.

A aproximação com a discussão de Fausto (2008) torna-se bastante evidente quando digo que as mulheres com quem estive no Icatu são donas de suas casas porque elas the conferem controle e cuidado, não apenas em termos físicos das edificações, mas também de todas as relações que passam por aquele espaço, de todos os que habitam e circulam por esses domínios. 0 que envolve parentes adultos e crianças, animais, comida, artesanato, roça.

Voltando para a rotina da casa, seu espaço interno é ocupado por pessoas diferentes em momentos específicos do dia: as mulheres são responsáveis pelo preparo das refeições, e pelo trabalho de arrumação da cozinha, como lavar as panelas e pratos. Por isso, as mulheres costumam passar grande parte de seu tempo nas cozinhas de suas casas. Quando casadas, as filhas fazem esse serviço na cozinha de sua própria casa e quando solteiras, na cozinha da casa de sua mãe.

A espacialidade das casas envolve varanda, quintal e roça. A maioria das casas possui uma roça particular. A roça, atrás da casa, é frequentada uma ou duas vezes por dia pelas mulheres que cuidam da alimentação dos animais de criação como porcos e galinhas, além da dedicação habitual para plantação e colheita. Não se vai à roça no período da noite nem no final da tarde, quando o sol baixou. É bastante prestigioso para uma mulher possuir/cuidar de uma roça com diversidade de alimentos, animais e plantas medicinais. É comum que um filho 
recém-casado procure sua mãe para pedir alguma muda ou alguma planta para cura de alguma indisposição física, a mais recorrente é dor de barriga das crianças.

Assim, as casas Kaingang são espaços preferenciais de convívio das mulheres (avós, mães, tias, filhas e netos) e quanto mais autossuficiente for esse espaço, mais próximo do ideal de perfeição ela fica. Não precisar sair do espaço da casa para cumprimento de suas necessidades é desígnio de prestígio das mulheres, donas das casas. É importante seguir a vida sem a necessidade de se visitar outras casas, exceto em alguns raros momentos, de forma que a restrição constitui-se idioma preferencial das relações entre casas.

\section{NÃO VISITAÇÃO ENTRE CASAS E ETIQUETAS DE CONVIVIALIDADE}

0 circuito de visitação entre pessoas de casas distintas na aldeia Icatu é altamente controlado e observado pelas mulheres das casas mais prestigiosas. Uma pessoa que é vista entrando e saindo de casas que não a de sua mãe, tornase alvo de críticas e reprimendas. 0 mesmo se passa com as crianças que devem permanecer na casa de sua mãe ou avó materna para ser considerada pessoa respeitosa, comedida, característica bastante apreciada entre os moradores da aldeia.

Desde 0 início de minha pesquisa de campo fui devidamente informada de como eu deveria me comportar. Da série de recomendações, a mais sublinhada foi a definição das duas casas que eu poderia frequentar. Foi expressamente avisado a mim que eu não deveria visitar casas a meu bel prazer, para evitar que as fofocas entre as casas atrapalhassem a vida das pessoas da aldeia. Logo entendi que frequentar duas casas já era excesso, mesmo que, inicialmente, invadiu-me a sensação de que a existência dos Kaingang da aldeia Icatu era demasiadamente calma e sorrateira, quase imperceptível a olhos destreinados. Demorei a entender a vantagem analítica que a restrição de minhas visitações a duas casas poderia trazer para minhas análises, e por vezes, a sensação era de que eu não estava realizando corretamente as práticas que uma pesquisa de campo supõe.

Durante o tempo que passei na aldeia pude perceber que a lógica das visitações restritas entre pessoas de casas diferentes são vivenciadas também pelas crianças que circulam preferencialmente apenas entre as casas de suas mães e avós e não costumam passar as tardes na casa de outra criança para brincar. Isso mostra o quanto a evitação de visitações entre casas é um valor positivo e altamente cultivado pelos Kaingang da aldeia Icatu, visto que, desde a infância, prioriza-se a convivialidade ao espaço das casas das mães e avós maternas. 
Além das casas, a etiqueta da boa convivialidade envolve outra série de etiquetas de comedimento, como entre algumas categorias de pessoas: homens e mulheres; adultos e crianças.

Esse tipo de etiqueta de comedimento, respeito, vergonha como algo positivamente valorizado no trato social entre as pessoas, pode ser aproximado ao conceito mẽbêngôkre de pia'm, traduzido pelos antropólogos especialistas como vergonha e respeito (COHN, 2000, 2006). Tal associação é produtiva, mas não equivalente. A noção de pia'm envolve o cultivo de etiquetas de vergonha/respeito entre relações específicas interpessoais e não entre membros de casas distintas. Segundo Cohn (2000a, 2000b), pia'm prioriza a relação de vergonha/respeito que é cultivada por crianças em relação aos adultos. A diferença para os Kaingang da aldeia Icatu é que, entre os Xikrin, essa demonstração de vergonha/respeito por parte das crianças muitas vezes é ridicularizada pelos adultos que zombam das crianças por sua falta de habilidade ou traquejo social.

As crianças Kaingang da aldeia Icatu não ocupam todos os espaços da aldeia e não são vistas circulando entre as casas, não são mensageiras entre as casas. As pessoas não circulam entre qualquer casa e as crianças não frequentam outras casas além das suas e das suas avós maternas. Claro que tais afirmações não devem ser levadas ao pé da letra, como se as crianças nunca saíssem das casas de suas mães ou avós. De toda forma, os casos em que visitações entre membros de casas distintas eram raros e se restringiam a eventos comemorativos como: aniversários, festas de final de ano, dia do índio.

A organização de eventos comemorativos só contava com a participação das pessoas de todas as casas quando eram realizados em espaços gerais da aldeia, como na escola. Eventos realizados no espaço físico da escola tinham adesão de todas as casas. Por outro lado, eventos comemorativos mais privativos como aniversários e comemorações de final de ano, realizados no quintal de alguma das casas, não contava com a adesão total das casas da aldeia. Algumas casas estavam autorizadas a participar da festividade de outras, num cálculo complicado que vincula relações matrimoniais e de associações políticas.

Participei, ao lado das minhas anfitriãs, de dois aniversários de criança em casas em que não costumava frequentar, além de almoços de natal e ano novo. Tais eventos enchiam a casa de parentes e alguns convidados. Durante esses eventos as mulheres ficam juntas, sentam-se próximas e os homens repetem 0 procedimento. Nesses dias, a comida é farta e as mulheres da mesma casa ficam mais perto umas das outras. As crianças misturam-se cautelosamente aos convidados, de forma que irmãos e irmãs quase não se distanciam. Passada a fase 
da comilança, as mulheres se organizam no auxílio da limpeza dos pratos, panelas e divisão de "quentinhas" que serão levadas pelos convidados. Todos levam algo da festa para casa: carne, bolo, pão, macarrão, doce. Quem faz essa divisão é a dona da casa onde foi realizada a festa e vai entregando para as mulheres da outra casa, que vão se arrumando para ir embora. Cada vez que um prato com parte do que foi servido é entregue a uma convidada, ela responde no sentido de recusa: "Não precisa". Mas, a recusa nunca se efetua e cada uma das mulheres leva consigo um prato com as guloseimas separadas pela dona da casa, neste caso, a dona da comida servida.

A etiqueta da visita em dia de festa na casa de outra mulher é a discrição. As convidadas vão chegando e sentam-se mais próximas de suas filhas ou mães, perto daquelas com quem convivem em suas próprias casas. Não se levantam e nem pedem nada até serem servidas pela dona da festa. A comida fica exposta na mesa e é papel da anfitriã estar atenta se todas suas convidadas estão sendo servidas, de forma que a anfitriã passa o tempo todo servindo a comida àquelas que não se levantaram para ir à mesa. As crianças são alimentadas na maior parte do tempo por suas mães e não pedem nada diretamente à dona da festa.

Os homens vivenciam esses encontros de maneira específica. Formam suas rodas de conversa e o marido da dona da casa é quem pede alguma bebida ou comida para servir seus convidados. Assim, a mulher da casa onde a festa está ocorrendo é quem se aproxima mais do círculo masculino. É comum as mulheres convidadas irem embora e seus maridos continuarem na festa. Em geral quando as mulheres organizam sua retirada não há despedida ou negociação sobre a permanência do marido na festa. Quem cuida dos procedimentos de partida das convidadas é a anfitriã. As mulheres vão embora sem dizer nada aos seus maridos. Elas se despedem da dona da casa e rumam para sua própria.

Tais festas não são oferecidas para a totalidade da aldeia, os convidados são aqueles que mantêm maior proximidade de parentesco/convívio com a casa anfitriã. As famílias/casas que possuem um ingrediente Kaingang são mais próximas e se convidam a participar de eventos e festividades, 0 mesmo ocorre para as famílias/casas dos Terena, que festejam entre suas casas. As mulheres Terena, casadas com os homens Kaingang, que são convidados para os eventos, costumam acompanhar seus maridos; enquanto que os homens Terena, casados com mulheres Kaingang, também acompanham suas esposas, embora em menor número.

Numa outra ocasião, fui convidada a almoçar na casa de uma mulher Terena, velhinha e avó de muitas crianças. Esse convite envolvia uma ação de 
agradecimento por ter acompanhado dois de seus netos no processo seletivo para vestibular em São Carlos. Aceitei o convite. No dia do almoço, tendo avisado minha anfitriã, tive de almoçar também na casa onde eu era recebida. "Fiz o almoço mais cedo para você, lá eles demoram muito para almoçar, não fazem comida na hora certa". Depois de ter almoçado em casa segui rumo à região das casas Terena. Era sábado e o cardápio era churrasco. Percebo então que os maridos Kaingang das mulheres Terena, vinculadas àquela casa, não participavam do evento. Em resumo, não haviam pessoas de casas Kaingang na festa. "Eles gostam mais de ficar entre eles", constatou a mulher Terena.

0 cotidiano da aldeia Icatu mostrou que os princípios da convivialidade para o cultivo de uma vida boa relacionam-se com características como comedimento, descrição, não visitação entre casas. Mesmo em eventos de festas e eventos, nota-se uma série de medidas de precaução, a fim de não ser percebido como um convidado espaçoso, folgado, uma pessoa não respeitadora. Esses princípios fazem da aldeia Icatu um lugar sorrateiro, onde as crianças cultivam suas relações de respeito para com os adultos de sua própria casa e de casas alheias. Sem ter acesso ao ponto de vista das crianças como privilegiado, fui catapultada para as casas e varandas de duas mulheres, que além de me ensinarem as formas adequadas de me comportar, tiveram a árdua tarefa em lidar com minha presença desajeitada ao longo do período da pesquisa, tentando me transformar num tipo menos barulhento de pessoa. Como ouvi repetidas vezes: "Ora Thais, pare de gesticular os braços, por acaso você é macaca?". A pessoa respeitosa deve evitar quaisquer excessos de comunicação, tarefa bastante difícil para antropólogos.

\section{REFERÊNCIAS}

ALMEIDA, Ledson Kurtz de. Dinâmica religiosa entre os Kaingang do posto indígena Xapecó-SC. 1998. Dissertação (Mestrado em Antropologia Social) Universidade Federal de Santa Catarina, Florianópolis: 1998.

BORELLI, Silvia Simões. Os Kaingang no Estado de São Paulo: constantes históricas e violência deliberada. In: COMISSÃO PRÓ-INDIO. Índios no estado de São Paulo: resistência e transfiguração. São Paulo: YANKATU, 1984. p. 45-83.

CAMPOS, Keló-Maurício Pedro. Kaingang: Pyry Nhenpe'ti. Kaingang: um sonhador. Penápolis: FAPESP, 1999. 
COHN, Clarice. Noções de infância e desenvolvimento infantil. Cadernos de Campo, São Paulo, ano 10, n. 9, p. 15-25, 2000a.

COHN, Clarice. A criança indígena: a concepção Xikrin de infância $e$ aprendizado. 2000. Dissertação (Mestrado em Antropologia) - Universidade de São Paulo, São Paulo, 2000b.

COHN, Clarice. Antropologia da criança. Rio de Janeiro: Jorge Zahar, 2005.

COHN, Clarice. Relações de diferença no Brasil Central: os Mebengokre e seus outros. 2006. Tese (doutorado em antropologia) - Universidade de São Paulo, São Paulo, 2006.

CUNHA, Manuela Carneiro da. Os direitos do índio: ensaios e documentos. São Paulo: Brasiliense, 1987.

D’ANGELIS, Wilmar da Rocha. A língua Kaingang, a formação de professores e 0 ensino escolar. In: Seminário de Educação Escolar Indígena da Região Sul, 1., 1998, Balneário Camboriú. Anais... Balneário Camboriú: MEC, 1998.

D'ANGELIS, Wilmar da Rocha. Fonologia do Kaingang: dialeto do Toldo Chimbangue (SC): exercício de aplicação de um modelo não linear. 1992. Monografia (Dissertação) - Instituto de Estudos da Linguagem, UNICAMP, Campinas, 1992.

D'ANGELIS, Wilmar da Rocha. O primeiro século de registro da língua Kaingang (1842-1950): valor e uso da documentação etnográfica, 2003. Disponível em: < http://www.portalkaingang.org/Primeiros100anos.pdf>. Acesso em: 30 jun. 2014.

FAUSTO, Carlos. Donos demais: maestria e domínio na Amazônia. Mana, Rio de Janeiro, v.14, n. 2, p. 329-366, 2008.

FERNANDES, Ricardo Cid. Autoridade política Kaingang: um estudo sobre a construção da legitimidade política entre os Kaingang de palmas/Paraná. 1998. Dissertação (Mestrado em Antropologia Social) - Universidade Federal de Santa Catarina, Florianópolis, 1998.

HAVERROTH, Moacir. Kaingang, um estudo etnobotânico: o uso e a classificação das plantas na Área Indígena Xapecó (oeste de SC). 1997. Dissertação (Mestrado em Antropologia Social) -Universidade Federal de Santa Catarina, Florianópolis, 1997.

LEA, Vanessa. Casas e casas Mebengokré. In: CASTRO, E. V.; CUNHA, M. C.; DREYFUS, S. (Org.). Amazônia: etnologia e bistória indígena. São Paulo: Ed. NHII/USP/FAPESP, 1993. 
LEA, Vanessa. Desnaturalizando gênero na sociedade Mebengokré. Estudos Feministas, Porto Alegre, v. 7, n. 1-2, p. 176-194, 2000.

LEA, Vanessa. Gênero feminino Mebengokré (Kayapó): desvelando representações desgastadas. Cadernos Pagu, Campinas, n. 3, p. 85-116, 1994.

LEA, Vanessa. Nomes e Nekrets Kayapó: uma concepção de riqueza. 1986. Tese (Doutorado em Antropologia Social) - Universidade Federal do Rio de Janeiro, Rio de Janeiro, 1986

LEA, Vanessa. Riquezas intangíveis de pessoas partíveis. São Paulo: EDUSP, 2012.

LÉVI-STRAUSS, Claude. La Voie des Masques, édition revue, augmentée, et rallongée dee Trois Excursions. Paris: Plon, 1979.

LÉVI-STRAUSS, Claude. Tristes trópicos. Buenos Aires: Eudeba, 1970.

MANIZER, Henrich H. Os Kaingang de São Paulo. Campinas: Curt Nimuendajú, 2006.

MANTOVANELLI, Thais. Crianças invisiveis da reserva Icatu SP. 2012. Dissertação (Mestrado em Antropologia) - Universidade Federal de São Carlos, São Carlos, 2012.

MANTOVANELLI, Thais. De dentro dos quintais: relações de espaço e família para crianças indígenas da Reserva do Icatu SP. In: PEGGION, E.; DANAGA, A. (Org.). Povos indígenas em São Paulo: novos olhares. São Carlos: Ed. UFSCar, 2014. No prelo.

MAYBURY-LEWIS, David. (Ed.) Dialectical Societies: the Gê and Bororo of Central Brazil. Cambridge: Harvard University Press, 1979.

MENGET, Patrick. Em nome dos outros: classificação das relações sociais entre os Txicão do Alto Xingu. Lisboa: Assírio e Alvim, 2001.

MONTEIRO, John. Vida e morte do índio: São Paulo colonial. In: COMISSÃo PRÓINDIO. Índios no estado de São Paulo: resistência e transfiguração. São Paulo: YANKATU, 1984. p. 21-45.

MOTA, Lúcio Tadeu. As Guerras dos Índios Kaingang: a bistória épica dos indios Kaingang no Paraná (1769-1924). EDUEM, 1998.

OVERING, Joanna. A estética da produção: o senso de comunidade entre os Cubeo e os Piaroa. Revista de Antropologia, São Paulo, v. 34, p. 7-33, 1991. 
OVERING, Joanna. Elogio do cotidiano: a confiança e a arte da vida social em uma comunidade amazônica. Mana, Rio de Janeiro, v. 5, n. 1, p. 81-107, 1999.

RIBEIR0, Darcy; BARBOSA, L. B. H. Relatório dos trabalhos realizados pela inspetoria do SPI em São Paulo durante o ano de 1916. Revista Museu Paulista, São Paulo, v. 8, 1954.

ROSA, Rogério Reus Gonçalves. A rítmica da lua na luta pela terra dos Kaingang de Iraí. In: TOMMASINO, Kimiye; MOTA, Lúcio Tadeu; NOELLI, Francisco S. (Org.). Novas contribuições aos estudos interdisciplinares dos Kaingang. Londrina: EDUEL, 2004.

SANTOS, Silvio Coelho dos. Índios e brancos no Sul do Brasil: a dramática experiência dos Xokleng. Floranópolis: Edeme, 1973.

SCHADEN, Egon. A origem dos homens, o dilúvio e outros mitos Kaingang. Revista de Antropologia, São Paulo, p. 139-141, 1953.

SCHADEN, Egon. A representação do dualismo Kaingang no mito tribal. In: . A mitologia heróica de tribos indígenas do Brasil. Rio de Janeiro: Ministério da Educação e Cultura, 1959. p. 103-116.

SILVA, Aracy Lopes da. Pequenos "xãmas": crianças indígenas, corporalidade e escolarização. In: SILVA, Aracy Lopes da; NUNES, Angela; MACED0, Ana Vera (Org.). Crianças indígenas: ensaios antropológicos. São Paulo: Global, 2002.

TOMMASINO, Kimiye. A bistória dos Kaingang da bacia meridional do Tibagi, uma sociedade Jê meridional em movimento. 1995. Tese (Doutorado em Antropologia Social) - Universidade de São Paulo, São Paulo, 1995.

URBAN, Greg. A model of Shokleng social reality. Chicago: University of Chicago, 1978.

VEIGA, Juracilda. Organização social e cosmovisão Kaingang: uma introdução ao parentesco, casamento e nominação em uma sociedade Jê Meridional. Dissertação (Mestrado em Antropologia Social) - Instituto de Filosofia e Ciências Humanas, UNICAMP, Campinas, 1994.

VEIGA, Juracilda. Cosmologia e práticas rituais Kaingang. Tese (Doutor em Antropologia Social) Instituto de Filosofia e Ciências Humanas, UNICAMP, Campinas, 2000. 